\title{
ANALISIS KESANTUNAN BERBAHASA \\ DALAM DIALOG KOMUNIKASI TERAPEUTIK ANTARA BIDAN DENGAN IBU HAMIL
}

\author{
Herlina Lindaria Simanjuntak \\ Universitas Indraprasta PGRI, Jakarta \\ 081282132773 \\ herlinalindaria12@gmail.com
}

Received August 7,2020; Revised August 12, 2020; Approved Oct 15, 2020

\begin{abstract}
ABSTRAK
Penelitian ini membahas tentang kesantunan berbahasa dalam dialog komunikasi terapeutik antara bidan dengan ibu hamil di klinik praktek kebidanan di daerah Depok. Tujuan penelitian ini adalah untuk mengetahui penaatan dan pelanggaran prinsip kesantunan Leech dalam komunikasi terapeutik antara bidan dan ibu hamil di klinik praktek kebidanan pada Klinik Bidan Emmy, yang terletak di Jalan Kemakmuran, Mekarjaya, Kecamatan Sukmajaya, Depok. Sumber data dari penelitian ini adalah dialog komunikasi terapeutik antara bidan dan ibu hamil yang dikumpulkan melalui teknik rekam catat. Metode yang digunakan dalam penelitian ini adalah penelitian kualitatif dengan menggunakan metode deskriptif. Kesantunan berbahasa yang diteliti dalam penelitian ini adalah yang mengandung prinsip sopan santun teori Leech, prinsip sopan santun itu meliputi enam maksim yaitu (1) maksim kebijaksanaan (2) maksim kedermawanan, (3) maksim penghargaan, (4) maksim kesederhanaan, (5) maksim pemukatan, dan yang terakhir maksim simpati. Hasil penelitian ini, yakni terdapat tuturan, baik yang memenuhi maupun yang melanggar prinsip kesantunan Leech. Tuturan yang memenuhi prinsip Leech lebih banyak bila dibandingkan dengan tuturan yang melanggar prinsip kesantunan Leech.
\end{abstract}

Kata Kunci: kesantunan, komunikasi terapeutik, bidan, ibu hamil

\begin{abstract}
This study discusses language politeness in therapeutic communication dialogue between midwives and pregnant women in midwifery practice clinics in Depok area. The purpose of this study was to determine the compliance and violation of the Leech politeness principle in therapeutic communication between midwives and pregnant women at the midwifery practice clinic at the Emmy Midwife Clinic, which is located on Jalan Kemakmuran, Mekarjaya, Sukmajaya District, Depok. The data source of this study is a dialogue of therapeutic communication between midwives and pregnant women which is collected through a record technique. The method used in this research is qualitative research using descriptive methods. Language politeness studied in this study contained the principles of the Leech theory of courtesy, the principles of courtesy include six maxims, namely (1) maxim of wisdom (2) maxim of generosity, (3) maxim of appreciation, (4) maxim of simplicity, (5) maxim of trawling, and the last maxim of sympathy. The result of this research is that there are utterances, both those that fulfill and those that violate the principles of Leech politeness. There are more speeches that fulfill the Leech principles than those that violate the Leech's principle of politeness.
\end{abstract}

Keywords: politeness, therapeutic communication, midwives, pregnant women 
Jurnal Pujangga Volume 6, Nomor 2, Desember 2020

ISSN P 2443-1478

ISSN E 2443-148

\section{PENDAHULUAN}

\section{Latar Belakang}

Manusia diciptakan sebagai makhluk multidimensi, memiliki akal pikiran dan kemampuan berinteraksi secara personal maupun sosial. Karena itu, manusia disebut sebagai makhluk yang unik, memiliki kemampuan sosial sebagai makhluk individu dan makhluk sosial. Manusia merupakan makhluk sosial yang membutuhkan kehadiran orang lain dalam kehidupannya. Adanya kehadiran orang lain di sekitarnya menimbulkan interaksi yang membutuhkan komunikasi di antara mereka untuk dapat menyampaikan perasaan, ide, keinginan, dan lain sebagainya.

Menyampaikan perasaan, ide, dan keinginan dapat tersampaikan dengan baik jika dikomunikasikan dengan baik pula. Tidaklah heran banyak dari kita, manusia belajar berkomunikasi baik di lembaga-lembaga non formal maupun lembaga formal, seperti berkuliah di jurusan komunikasi. Begitu pentingnya mempelajari komunikasi, apalagi di era globalisasi ini, karena komunikasi adalah suatu proses di mana seseorang atau sekelompok orang, baik dalam organisasi maupun dalam masyarakat menciptakan dan menggunakan informasi agar terhubung dengan lingkungan dan orang lain. Thomas M. Scheidel mengemukakan bahwa kita berkomunikasi terutama untuk menyatakan dan mendukung identitas-diri, untuk membangun kontak sosial dengan orang sekitar kita, dan untuk mempengaruhi orang lain untuk merasa, berpikir, atau berprilaku seperti yang kita inginkan. Menurut Scheidel, tujuan dasar kita berkomunikasi adalah untuk mengendalikan lingkungan fisik dan psikologis kita (Mulyana, 2008: 4).

Berbicara tentang komunikasi, bahasa erat hubungannya dengan pragmatik, yakni syaratsyarat yang mengakibatkan serasi tidaknya pemakaian bahasa dalam komunikasi. Konsep-konsep pragmatik adalah kajian tentang tiga konsep dalam interaksi komunikatif, yaitu makna, konteks dan komunikasi. Dalam menafsirkan suatu tuturan, seseorang harus memperhatikan tindak tuturnya. Karena itu, agar tercapainya tujuan penutur kepada mitra tuturnya atau lawan bicaranya, maka diperlukanlah kesantunan dalam berbahasa.

Kondisi pragmatik, yaitu apa maksud penutur, apa motivasi yang memicu maksud itu, situasi dengan siapa, kapan dan dimana ia berbicara (Gunarwan, 2007). Untuk dapat menyampaikan maksud kepada mitra tuturnya, seorang penutur harus dapat memilih dan menggunakan bahasa dengan tepat. Ketepatan pemilihan ragam bahasa sangat berpengaruh terhadap kelancaran komunikasi.

Berdasarkan paparan di atas, peneliti menganalisis aspek kesantunan teori Leech dalam dialog komunikasi terapeutik antara bidan dan ibu hamil pada klinik praktek kebidanan di daerah 
Jurnal Pujangga Volume 6, Nomor 2, Desember 2020

ISSN P 2443-1478

ISSN E 2443-148

Depok, yakni Klinik Bidan Emmy, yang terletak di Jalan Kemakmuran, Mekarjaya, Kecamatan Sukmajaya, Depok. Komunikasi terapeutik ini penting karena cara berkomunikasi bidan berpengaruh terhadap ketenangan dan perasaan nyaman pada ibu hamil dalam menghadapi masa kehamilan kehamilan pertamanya yang merasa sungkan untuk pergi memeriksakan kehamilannya ke bidan. Mereka merasa riskan, malu, takut, apalagi jika cara bidan tersebut bertutur agak kurang berkenan di hati para ibu hamil tersebut. Bahkan tidak sedikit para ibu muda yang hamil pertama merasa stress ketika pertama kali berkomunikasi dengan bidan. Tentu saja hal tersebut, yaitu stres yang dialami oleh pasien akan berpengaruh kepada janin yang dikandungnya. Akibatnya, bukan tidak mungkin para ibu hamil tersebut malas atau bahkan tidak akan kembali memeriksakan kehamilan mereka ke bidan yang sama. Tentu hal ini tidak baik bagi bagi psikologis si ibu hamil. Menurut Sunaryo dalam Patty "Semua manusia cenderung akan mengalami stress dalam kehidupannya (2015)". Karena itu dibutuhkan komunikasi yang baik antara bidan dan pasiennya, dalam hal ini ibu hamil, sebagai alasan agar pasien merasa nyaman dan terjadilah proses interaksi, sehingga terjadilah pertukaran informasi serta dukungan selama pasien tersebut stress. Jika pasien merasa komunikasi bidan dengannya tidak nyaman, maka ia akan pindah ke bidan yang lain, sementra itu bidan keduapun sudah tentu tidak memiliki data medis sebelumnyua, karena itulah komunikasi terapeutik sangatlah diperlukan bagi seorang bidan. "Seluruh perilaku dan pesan yang disampaikan perawat hendaknya bertujuan terapeutik untuk pasien" (Rusmini, 2006:26). Hasil penelitian Rusmini mendapatkan, bahwa perilaku perawat di RSU Palangkaraya kurang baik dalam berkomunikasi dengan baik. Padahal kita tahu, pasien akan merasa tidak nyaman dan akan mengalami stres jika perawat tidak berkomunikasi dengan baik.

Keberhasilan komunikator dapat dievaluasi dari sudut seberapa jauh tujuan-tujuan komunikator tersebut dicapai dan persyaratan akan keberhasilan komunikasi ialah jika mendapat perhatian. "Hubungan yang membantu komunikasi terapeutik meliputi rasa percaya, empati dan perhatian sehingga tingkat kecemasan keluarga pasien tergolong ringan" (Potter dan Perry, 2005). Oleh karena itu, dalam melakukan komunikasi antara bidan dan pasien harus membuat si pasien merasa nyaman, sehingga pasien tidak akan merasakan kecemasan, karena ia percaya kepada bidan. Sebaliknya, jika bidan menyampaikan pesan kepada pasiennya tetapi diabaikan, maka usaha komunikasi tersebut akan gagal, karena itu, keberhasilaan komunikasi juga tergantung kepada pemahaman pesan dan penerima. Jika penerima tidak memahami pesan tersebut, maka tidak mungkin berhasil dalam memberikan informasi atau mempengaruhinya. Bahkan jika suatu pesan tidak dimengerti, penerima mungkin tidak meyakini bahwa informasinya benar, sekalipun komunikasi benar-benar memberikan arti apa yang dikatakan (Hardjana, 2003: 85). Dapat 
Jurnal Pujangga Volume 6, Nomor 2, Desember 2020

ISSN P 2443-1478

ISSN E 2443-148

dikatakan bahwa jika seorang bidan tidak memiliki komunikasi terapeutik yang baik, maka apa yang disampaikan pada pasien akan sia-sia, karena pasien tidak akan memahami isi pesan tersebut. Hal ini sungguh membahayakaan, karena menyangkut kesehatan serta keselamatan jiwa ibu hamil dan calon bayi yang kelak akan menjadi penerus bangsa ini.

Keterampilan berkomunikasi merupakan skil yang harus dimiliki oleh seorang bidan dan merupakan bagian integral dari asuhan kebidanan. Keberhasilan seorang bidan untuk dapat meyakinkan pasiennya, merupakan dasar dari sebuah keberhasilan komunikasi. Komunikasi dalam kebidanan disebut dengan komunikasi terapeutik, yang merupakan komunikasi yang dilakukan oleh seorang bidan terhadap pasien ditujukan untuk mengubah perilaku klien ke arah yang lebih baik agar mencapai tingkat kesehatan yang optimal (Stuart dan Larala, 2011) (Suryani, 2013:15).

Berdasarkan paparan di atas, dapat diketahui jika komunikasi memegang peranan penting dalam keberhasilan suatu program, yaitu program menyehatkan ibu hamil serta bayi yang dikandungnya. Agar hal itu tercapai, bidan harus mampu menjalin hubungan baik dengan pasien, mampu menggunakan komunikasi terapeutik yang baik kepada pasien dan keluarga. Sehingga akan timbul rasa percaya pasien kepada bidan. Pasienpun merasa nyaman dan tidak menjadi stress. Apalagi bagi pasien yang baru pertama kalinya hamil dan memeriksakan kehamilannya kepada bidan. Bidan juga menjadi pendengar baik atas keluhan. Karena itu, rumusan masalah yang ditetapkan oleh peneliti adalah menganalisis kesantunan berbahasa dalam dialog komunikasi terapeutik kebidanan Depok.

\section{Rumusan Masalah}

Berdasarkan latar belakang dan masalah, penelitian ini difokuskan pada masalah berikut.

1. Bagaimana penataan prinsip kesantunan Leech dalam komunikasi terapeutik antara bidan dan ibu hamil di klinik praktek kebidanan pada Klinik Bidan Emmy, yang terletak di Jalan Kemakmuran, Mekarjaya, Kecamatan Sukmajaya, Depok?

2. Bagaimana pelanggaran prinsip kesantunan Leech dalam komunikasi terapeutik antara bidan dan ibu hamil di klinik praktek kebidanan pada Klinik Bidan Emmy, yang terletak di Jalan Kemakmuran, Mekarjaya, Kecamatan Sukmajaya, Depok?

\section{Tujuan Penelitian}

Penelitian ini bertujuan untuk: 
1. mendeskripsikan dan menganalisis penataan prinsip kesantunan Leech dalam komunikasi terapeutik antara bidan dan ibu hamil di klinik praktek kebidanan pada Klinik Bidan Emmy, yang terletak di Jalan Kemakmuran, Mekarjaya, Kecamatan Sukmajaya, Depok.

2. mendeskripsikan dan menganalisis pelanggaran prinsip kesantunan Leech dalam komunikasi terapeutik antara bidan dan ibu hamil di klinik praktek kebidanan pada Klinik Bidan Emmy, yang terletak di Jalan Kemakmuran, Mekarjaya, Kecamatan Sukmajaya, Depok.

\section{Tinjauan Pustaka}

\section{Prinsip Kesantunan}

Salah satu aspek penting dalam kelancaran komunikasi, sehingga maksud dan tujuan penutur kepada lawan bicara atau mitra tutur tercapai adalah kesantunan berbahasa.

Berkomunikasi dengan mitra tutur tanpa kesantunan berbahasa, maka sia-sialah tujuan kita untuk menyampaikan pesan. Hal ini dapat terjadi karena sering sekali dalam berbahasa, kita melanggar maxim kesantunan berbahasa. Karena itu, dalam berinteraksi kita harus betul-betul memperhatikan prinsip kesantunan berbahasa.

Markhamah dan Atiqa Sabardila (2013: 15) menyatakan bahwa kesantunan merupakan suatu cara yang dilakukan penutur saat berkomunikasi supaya penutur tidak merasa tertekan, tersudut, dan tersinggung. Kesantunan berbahasa dalam hal ini berupaya untuk menjaga harga diri pembicara maupun pendengar. Penggunaan bahasa yang santun saat berkomunikasi akan membuat mitra tutur dan lawan bicara merasa dihormati, nyaman, dan tidak menimbulkan kesalah pahaman. Sehingga akan terciptra komunikasi yang baik. Apalagi bagi bangsa Indonesia yang terkenal akan kesantunanya dalam bertutut, maka sudah pasti, hal ini tidak asing lagi .Kesantunan sudan melekat dan menjadi budaya bagi masyarakat Indonesia.

Nadar (2013: 10) mengatakan bahwa kesopanan berbahasa dapat disebut kesantunan berbahasa yang dipakai penutur untuk mengurangi rasa tidak senang, tidak berkenan hati, atau sakit hati akibat tuturan yang diucapkan oleh penutur. Maksudnya, dengan komunikasi bahasa yang santun dapat menjadikan kegiatan berkomunikasi menjadi baik dan saling menghormati. Meskipun sebenarnya penutur marah atau tidak menyukai kepada mitra atau lawan bicaranya, tetapi karena menyampaikannya dengan kesatunan berbahasa, maka tid berkomunikasi atau berinteraksi dengan mitra tutur atau lawan bicara.

Rahardi (2005: 12) menyatakan bahwa Leech membagi prinsip kesantunan menjadi enam yang terdiri dari; Maksim Kebijaksanaan (Tact Maxim), Maxim Kedermawanan (Generosity 
ISSN P 2443-1478

ISSN E 2443-148

maxim), Maxim Penghargaan (Approbation Maxim), Maxim Kesederhanaan (Modesty Maxim), Maxim Permufakatan (Agreement Maxim), dan Maxim Simpati (Sympathy Maxim).

1. Maksim Kebijaksanaan (Tact Maxim) yaitu, mengurangi kerugian orang lain dan menambahi keuntungan orang lain

Contoh :

Ibu hamil : Bagaimana ya bu bidan, usia saya sudah lebih dari empat puluh tahun, tapi saya hamil lagi. Suami saya juga sudah tidak muda lagi. Anak saya yang paling kecil sudah kelas tiga SMA. Tapi suami saya malah sangat ingin mempunyai anak kecil lagi.

Bidan : Selamat ya bu. Ini karunia Tuhan. Yang penting ibu makan makanan yang bergizi dan rajin memerikasan kehamilannya.

2. Maksim Kedermawanan (Generosity Maxim) yaitu : mengurangi keuntungan diri sendiri dan menambahi pengorbanan diri sendiri

Contoh :

Bidan

Ibu Hamil

: Kalau sudah waktunya lahiran, langsung aja datang ke sini. Ga usah pakai janjian dulu. In syaa Allah saya siap kapan aja.

:Tenang saya dengernya bu bidan. Makasih banyak.

3. Maksim Penghargaan (Approbation Maxim) yaitu: mengurangi cacian pada orang lain dan menambahi pujian pada orang lain.

Contoh :

Ibu hamil

: Ini kehamilan saya yang ketiga bu. Kan lahiran yang dua di sini

Bidan juga bu bidan.

: Oh iya. Alhamdulillah tetep keliatan cantik, muda dan sehat. Ga mual-mual kan?

4. Maksim Kesederhanaan (Modesty Maxim) yaitu: mengurangi pujian pada diri sendiri dan menambahi cacian pada diri sendiri

Contoh:

Bidan

Ibu hamil

: Ibu terlihat segar hari ini

: Ah itu mungkin perasaan ibu saja. Kulit saya kusam bu

5. Maksim Permufakatan (Agreement Maxim) yaitu: mengurangi ketidaksesuaian antara diri sendiri dengan orang lain dan meningkatkan persesuaian antara diri sendiri dengan orang lain

Contoh: 
ISSN P 2443-1478

ISSN E 2443-148

Ibu hamil : Boleh ga bu bidan, kalau saya masih berolah raga seminggu tiga kali? Soalnya kalau saya gak olah raga badan saya pegal-pegal, bu bidan.

Bidan : Oh tentu boleh aja bu. Yang penting, ibu harus ingat, kalau ibu sedang hamil. Jadi jangan olah raga yang terlalu keras. Cukup jalan pagi santai saja, ya bu. Kalau bisa ditemani suami bu, olah raganya. Supaaya makin semangat bu

Contoh:

Ibu hamil: Ga apa-apa kali ya bu kalau saya masih ngerokok sekali kali?

Bidan : Tidak boleh ibu. Demi kesehatan bayi di dalam kandungan ibu, lebih baik berhenti merokoknya.

(Dialog melanggar maksim permufakatan karena bidan melarang ibu hamil untuk merokok)

6. Maksim Simpati (Sympathi Maxim) yaitu: mengurangi antipati antara diri sendiri dengan orang lain dan meningkatkan simpati antara diri sendiri dengan orang lain

Contoh:

Ibu hamil: Bu bidan, Saya muntah muntah. Ga bisa kalau nyium bau yang menyengat kayabau minyak wangi, masakan.

Bidan : Ga apa-apa. Biasanya hamil anak pertama keluhannya seperti itu. Mual, muntah itu akibat dari hormon kehamilan aja.

\section{Dialog}

Soenjono Dardjowidjojo (2005) yang mengatakan bahwa wacana dibagi menjadi dua macam (a) dialog dan (b) monolog. Perbedaan utama dari dua macam ini terletak pada ada tidaknya interaksi antara pembicara dengan pendengar. Pada dialog terdapat paling tidak dua pelaku, yakni yang berbicara dan yang diajak berbicara (interlokutornya). Pada monolog, hanya ada satu pembicara, kalau wacana itu tulisan, hanya penulis sebagi pelakunya.

Mengenai wacana monolog, dialog, dan plolilog menurut Djayasudarma (2006) menambahkan hal yang hampir senada bahwa wacana monolog merupakan wacana yang tidak melibatkan dua pihak yang berkepentingan. Jenis wacana ini berupa surat, bacaan, cerita, dan lainlain. Wacana yang berwujud dialog berupa percakapan atau pembicaraan antara dua pihak terdapat koversasi.

\section{Komunikasi Terapeutik}

Orang-orang secara tatap muka yang memungkinkan setiap pesertanya menangkap reaksi orang lain sacara langsung, baik secara verbal dan nonverbal (Mulyana, 2005). Komunikasi 
Jurnal Pujangga Volume 6, Nomor 2, Desember 2020

ISSN P 2443-1478

ISSN E 2443-148

terapeutik banyak terjadi di dunia kesehatan, salah satunya di klinik praktek kebidanan atau rumah bersalin. Komunikasi terapeutik antara bidan dengan pasien sangatlah penting. Karena komunikasi terapeutik dapat menyokong kesehatan pasien. Hal ini dikarenakan, pasien akan merasa rileks, santai, nyaman, dan percaya dengan apa yang disampaikan oleh bitdan. Informasi tersampaikan dan pasien menuruti apa yang dikatakan oleh bidan, maka pasien akan merasa berterima kasih kepada bidan. Pasien juga akan semgat tiap kali memeriksakan kehamilannya. Pasien tidak memiliki ganjalan untuk menceritakan keluhan-keluhan yang dirasakannya kepada bidan.

Komunikasi terapeutik meningkatkan pemahaman dan membantu terbentuknya hubungan yang konstruktif di antara perawat dengan klien. Tidak seperti komunikasi sosial, komunikasi

terapeutik mempunyai tujuan untuk membantu klien mencapai suatu tujuan dalam asuhan keperawatan. Stuart dan Sundeen (Taufik, 2010) menjelaskan bahwa dalam prosesnya komunikasi terapeutik terbagi menjadi empat tahapan, yaitu tahap persiapan atau tahap pra-interaksi, tahap perkenalan atau orientasi, tahap kerja dan tahap terminasi.

Menurut Anthony (dalam Marlen, et. al. 2015:172) komunikasi terapeutik sangat penting dan merupakan komunikasi yang direncanakan secara sadar dan dipusatkan serta bertujuan untuk kesembuhan pasien.

\section{METODE PENELITIAN}

Pendekatan yang digunakan dalam penelitian ini adalah pendekatan pragmatik, yakni bagaimana bahasa itu digunakan dalam komunikasi. Pragmatik diartikan sebagai syarat-syarat yang mengakibatkan serasi-tidaknya pemakaian bahasa dalam komunikasi; aspek-aspek pemakaian bahasa atau konteks luar bahasa yang memberikan sumbangan kepada makna ujaran.

Penelitian ini adalah penelitian kualitatif dengan menggunakan metode deskriptif. Penelitian ini termasuk penelitian kualitatif karena penelitian ini berusaha memahami kesantunan berbahasa berdasarkan prinsip kesantunan Leech dalam komunikasi terapeutik. Hal ini sesuai dengan pendapat Moleong (2007) menyatakan bahwa penelitian kualitatif adalah penelitian yang bermaksud untuk memahami fenomena tentang apa yang dialami oleh subjek penelitian misalnya perilaku, persepsi, motivasi, tindakan, dan lain sebagainya secara holistik, dan dengan cara deskripsi dalam bentuk kata-kata dan bahasa, pada suatu konteks khusus yang alamiah dan dengan memanfaatkan berbagai metode alamiah

Peneliti menggunakan dua buah instrumen penunjang yakni telepon genggam untuk merekam komunikasi yang terjadi dan tabel analisis yang digunakan untuk mencatat data yang 
Jurnal Pujangga Volume 6, Nomor 2, Desember 2020

ISSN P 2443-1478

ISSN E 2443-148

terkait dengan masalah penelitian yaitu yang berupa kata-kata, frasa, klausa ataupun kalimat yang mengandung tuturan kesantunan yang didasarkan pada enam maksim.

Pengumpulan data dilakukan di klinik praktek kebidanan dengan teknik rekam dan catat. Tuturan yang terjadi saat komunikasi antara bidan dan ibu hamil direkam kemudian dicatat dan dianalisis.

Data dalam penelitian ini dianalisis melalui tahap transkripsi data, mengklasifikasi data, menganalis data, dan penarikan simpulan. Pada proses transkripsi data, komunikasi terapeutik yang telah direkam dijadikan transkrip dialog untuk memudahkan proses analisis data. Setelah itu transkrip dialog diklasifikasikan berdasarkan maksim dalam teori kesantunan leech. Data yang sudah diklasifikasikan dianalisis untuk mengetahui apakah terjadi penaatan atau pelanggaran prinsip kesantunan Leech. Tahap terakhir adalah menarik simpulan dari hasil analisis yang menjadi tujuan dari diadakannya penelitian ini.

Populasi penelitian merupakan keseluruhan dari obyek penelitian yang akan diteliti (Nursalam, 2001:56). Penelitian ini dilakukan pada Klinik Bidan Emmy, yang terletak di Jalan Kemakmuran, Mekarjaya, Kecamatan Sukmajaya, Depok, klinik kebidanan mandiri di Depok. Data yang diambil adalah dialog antara bidan dengan pasien, dalam hal ini ibu hamil

Sampel adalah bagian dari populasi yang dipilih dengan cara tertentu dan dianggap mewakili seluruh populasi (Nursalam,2001:58). Sampel dalam penelitian ini adalah para pasien dari Klinik Bidan Emmy, klinik bidan mandiri yang berlokasi di Depok. Peneliti hanya akan mengambil lima pasien dari tiap klinik bidan mandiri tersebut untuk dijadikan sampel. Dalam penelitian ini, peneliti menggunakan teknik purposive sampling, yaitu teknik pengambilan sampel secara sengaja. Peneliti menentukan sendiri sampel yang diambil tidak secara acak, tapi ditentukan sendiri oleh peneliti. Penelitian ini dilakukan selama tiga bulan, yakni mulai dari awal bulan Januari 2019 sampai dengan akhir bulan April 2019. Adapun sebelum melakukan penelitian, peneliti melakukan survey terlebih dahulu. Pengambilan data dilakukan selam tiga kali kunjungan.

\section{HASIL DAN PEMBAHASAN}

Tabel 1 Hasil Penaatan dan Pelanggaran Maksim

\begin{tabular}{crll}
\hline Maksim & Dialog & \multicolumn{1}{c}{ Bidan } & \multicolumn{1}{c}{ Ibu Hamil } \\
\hline Kebijaksanaan & & $\begin{array}{l}\text { Selamat ya bu. Tetap itu } \\
\text { namanya rezeki. Yang } \\
\text { penting ibu jaga kesehatan }\end{array}$ & $\begin{array}{l}\text { Bagaimana ya bu, anak } \\
\text { pertama saya belum }\end{array}$ \\
& 1 &
\end{tabular}


setahun umurnya, saya

udah hamil lagi.

Tidak masalah bu,

memang itu tugas saya sebagai bidan.

Aduuuhhh si ibu bagaimana sih, kan bulan lalu saya bilang, tidak boleh makan-makanan

3 seperti itu. Nanti rambut anaknya botak bu!!! Ibu susah benar sih dibilanginnya.
Saya jadi ngerepotin ibu lagi nih. Maaf ya bu bidan.

Bagaimana yah bu, sedang hamil muda begini, saya senangnya makan bakso yang panas, pedas dan asam.

\begin{tabular}{ll}
\hline Kedermawanan $\quad 4 \quad \begin{array}{l}\text { Kalau belum sempat } \\
\text { datang, kapan aja mau } \\
\text { tanya tanya lewat WA juga } \\
\text { ga apa-apa. Tapi tetap ya } \\
\text { bu usahakan datang } \\
\text { sebulan sekali biar akurat } \\
\text { pemeriksaan saya. }\end{array}$ \\
\\
$\begin{array}{l}\text { Kalau sudah waktunya } \\
\text { lahiran, langsung aja } \\
\text { datang ke sini. Ga usah } \\
\text { pakai janjian dulu. Insyaa } \\
\text { Allah saya siap kapan aja. } \\
\\
5 \quad \text { Kalau sampai rumah } \\
\text { kontraksinya hebat, ibu } \\
\text { boleh langsung datang saja } \\
\text { dan daftarnya boleh } \\
\text { belakangan }\end{array}$ \\
\hline
\end{tabular}

Kontraksi kehamilan saya

kuat sekali, bu. Paadahal

Makasih bu bidan. Ga apa ya tanya tanya pakai WA.

Tenang saya dengernya bu bidan. Makasih banyak ya.

kuat sekali, bu. Paadahal 


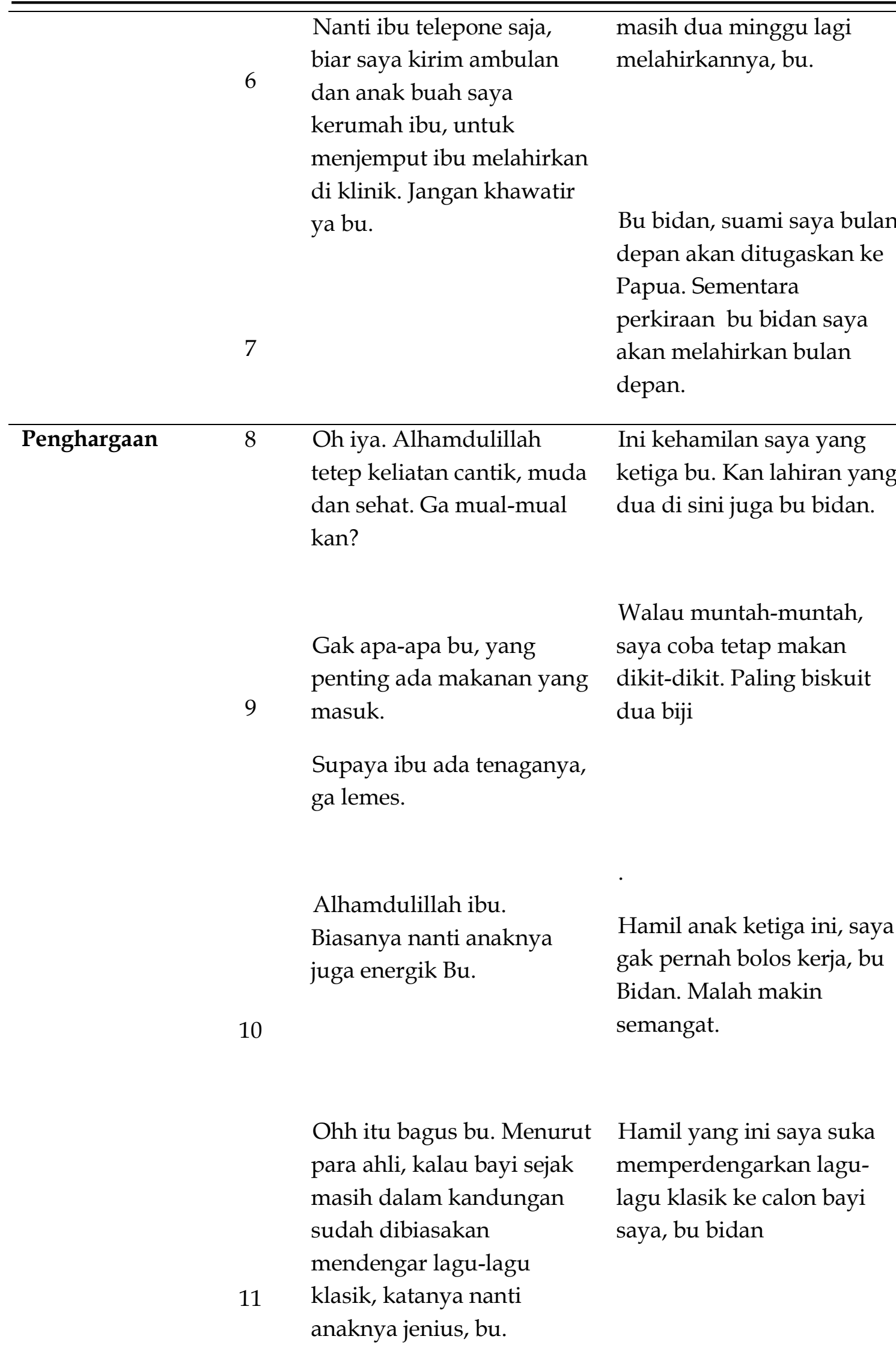




\begin{tabular}{|c|c|c|c|}
\hline \multirow[t]{3}{*}{ Kesederhanaan } & 12 & Ibu terlihat segar hari ini & $\begin{array}{l}\text { Ah itu mungkin perasaan } \\
\text { ibu saja. Kulit saya kusam } \\
\text { bu Bidan }\end{array}$ \\
\hline & 13 & $\begin{array}{l}\text { Alhamdulilah ya bu, } \\
\text { biarpun usia ibu tidak } \\
\text { muda lagi, tapi saya lihat } \\
\text { ibu tetap fit, dalam } \\
\text { kehamilan anak ke tiga ini, } \\
\text { bu. }\end{array}$ & $\begin{array}{l}\text { Bu bidan tidak tahu sih } \\
\text { kalau saya sebenarnya lagi } \\
\text { ruwet. }\end{array}$ \\
\hline & 14 & $\begin{array}{l}\text { Ibu kok naik angkot } \\
\text { padahal hamilnya sudah } \\
\text { besar, bu. Kenapa tidak } \\
\text { menggunakan kendaraan } \\
\text { pribadi saja. }\end{array}$ & $\begin{array}{l}\text { Saya lebih senang naik } \\
\text { angkot, bu bidan. }\end{array}$ \\
\hline
\end{tabular}

\section{Pemufakatan}

15 Boleh aja bu. Jangan terlalu kental tehnya. Coba juga kalau minum air putihnya yang hangat. Supaya mengurangi rasa mual.
Tidak boleh ibu. Demi kesehatan bayi di dalam kandungan ibu, lebih baik berhenti merokoknya.

Jangan bu. Apalagi usia ibukan beresiko tinggi untuk melahirkan di usia empat puluh lima.
Boleh ga bu kalau saya minumnya selalu pakai air teh? Kalo air putih saya suka mual mau muntah.

Ga apa-apa kali ya bu kalau saya masih ngerokok sekali kali?

Bu bidan, boleh gak saya memeriksakan 


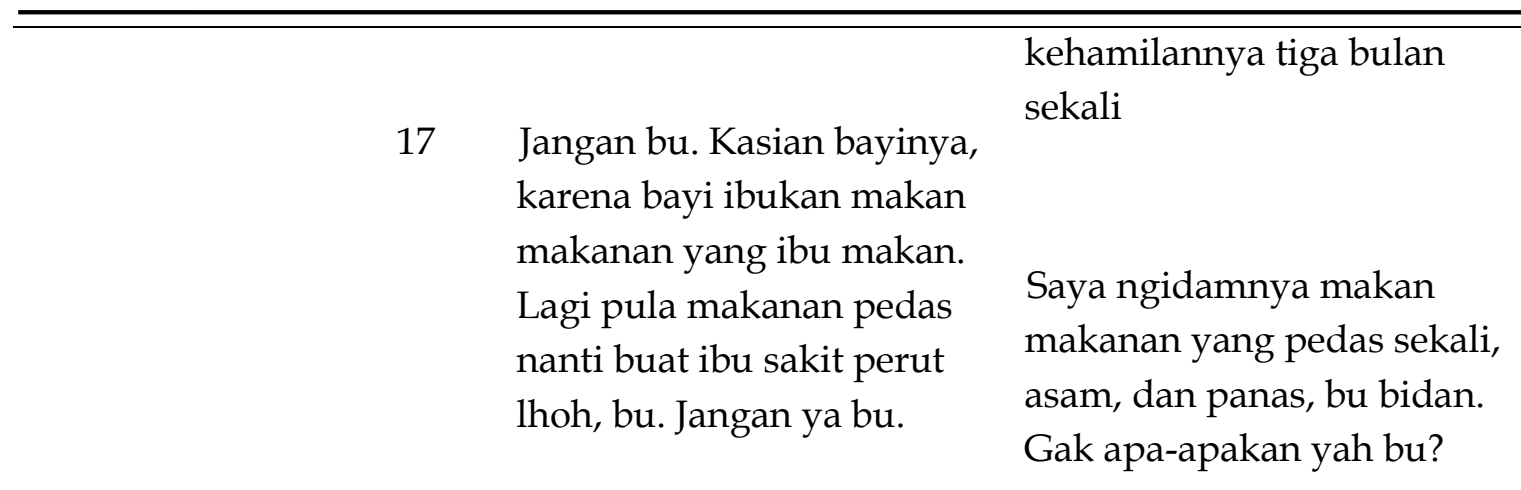

18

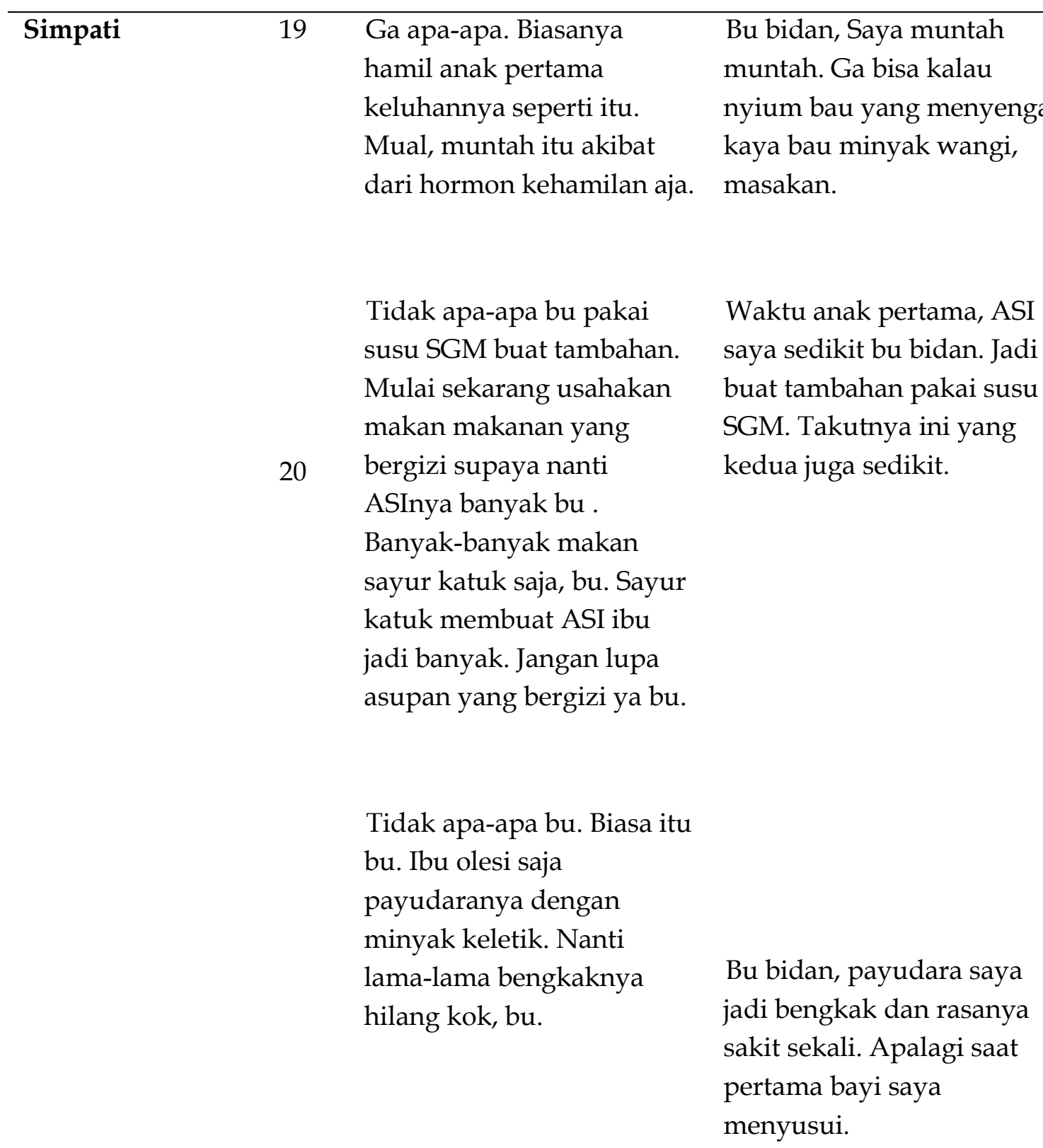


ISSN P 2443-1478

ISSN E 2443-148

\section{Pembahasan}

Dialog (1) Menaati maxim kebijaksanaan; mengurangi kerugian orang lain dan menambahi keuntungan orang lain, karena bidan menguicapkan selamat dan mengatan kehamilan pasien merupakan rezeki meskipun bidan mengetahui adalah kurang bagu jika si pasien sudah hamil lagi padahal anak pasien tersebut masih belum berusia satu tahun.

Dialog (2) Menaati maksim kebijaksanaan karena bidan berusaha memaksimalkan keuntungan bagi ibu hamil dengan tidak mempermasalahkan tindakan yang dilakukan oleh ibu hamil tersebut, yaitu hamil dengan jarak kehamilan yang sangat dekat.

Dialog (3) Tidak menaati maksim kebijaksanaan karena bidan berusaha tidak memaksimalkan keuntungan bagi ibu hamil dengan mempermasalahkan tindakan yang dilakukan oleh ibu hamil tersebut., yakni makan makanan yang pedas sekali, asam dan panas.

Dialog (4) menaati maksim kedermawanan; mengurangi keuntungan diri sendiri dan menambahi pengorbanan diri sendiri karena bidan mempersilakan ibu hamil tersebut untuk menghubunginya melalui media Whatsapp (WA) jika belum sempat datang ke klinik.

Dialog (5) menaati maksim kedermawanan karena bidan mempersilakan ibu hamil datang kapan saja ke klinik bersalin untuk melahirkan, bahkan boleh tanpa membuat janji terlebih dahulu. Hal ini membuat hati pasien merasa tenang.

Dialog (6) menaati maksim kedermawanan karena bidan mengatakan jika sampai rumah kontraksinya hebat, pasien langsung datang saja dan daftarnya boleh belakangan, karena bidan memahami kecemasan pasien akan kontraksi yang dihadapi.

Dialog (7) menaati maksim kedermawanan karena bidan mempersilahkan pasien untuk meneleponnya jika sang suami ditugaskan ke luar kota dan bidan akan mengirim ambulan untuk menjemput ibu melahirkan, sehingga pasien tidak khawatir.

Dialog (8) menaati maksim penghargaan; mengurangi cacian pada orang lain dan menambahi pujian pada orang lain, karena bidan memuji ibu hamil yang tetap terlihat cantik. 
ISSN P 2443-1478

ISSN E 2443-148

Dialog (9) menaati maksim penghargaan; mengurangi cacian pada orang lain dan menambahi pujian pada orang lain, karena bidan memuji ibu hamil yang tetap berusaha makan meskipun hanya dua keping biskuit.

Dialog (10) menaati maksim penghargaan; mengurangi cacian pada orang lain dan menambahi pujian pada orang lain, karena bidan mengatakan bahwa sang bayi kelak akan menjadi seorang yang energik.

Dialog (11) menaati maksim penghargaan; mengurangi cacian pada orang lain dan menambahi pujian pada orang lain, karena bidan mengatakan bahwa sang bayi kelak akan menjadi seorang yang jenius.

Dialog (12) menaati maksim keserdehanaan; mengurangi pujian pada diri sendiri dan menambahi cacian pada diri sendiri karena pasien mengatakan kulitnya kusam ketika bidan memuji betapa paisen terlihat segar.

Dialog (13) menaati maksim kesederhanaan; mengurangi pujian pada diri sendiri dan menambahi cacian pada diri sendiri, karena pasien mengatakan bahwa dirinya sedang ruwet, padahal bidan mengatakan bahwa biarpun usia pasien tidak muda lagi, tapi terlihat pasien tetap fit, dalam kehamilan anak ke tiganya.

Dialog (14) menaati maksim kesederhanaan; mengurangi pujian pada diri sendiri dan menambahi cacian pada diri sendiri, karena ibu hamil merasa tidak ada masalah pada kehamilannya meskipun naik angkot, padahal pasien memiliki mobil pribadi.

Dialog (15) menaati maxim pemufakatan; mengurangi ketidaksesuaian antara diri sendiri dengan orang lain dan meningkatkan persesuaian antara diri sendiri dengan orang lain, karena bu bidan menyetujui ibu hamil untuk minum teh.

Dialog (16) melanggar atau tidak menaati maksim permufakatan karena bidan melarang ibu hamil untuk merokok.

Dialog (17) melanggar atau tidak menaati maksim permufakatan karena bidan melarang ibu hamil memeriksakan kehamilannya tiga bulan sekali.

Dialog (18) melanggar atau tidak menaati maksim permufakatan karena bidan melarang ibu hamil makan makanan yang pedas sekali, asam, dan panas. 
ISSN P 2443-1478

ISSN E 2443-148

Dialog (19) menaati maksim; mengurangi antipati antara diri sendiri dengan orang lain dan meningkatkan simpati antara diri sendiri dengan orang lain, karena bidan menunjukkan rasa simpati kepada ibu hamil yang mengalami muntah-muntah pada masa kehamilan

Dialog (20) menaati maksim; mengurangi antipati antara diri sendiri dengan orang lain dan meningkatkan simpati antara diri sendiri dengan orang lain, karena bidan menunjukkan rasa simpati kepada ibu hamil yang memberikan tambahan susu formula kepada bayinya karena produksi ASInya sedikit.

Dialog (21) menaati maksim simpati karena bidan menunjukkan rasa simpati kepada pasien yang payudaranya bengkak dan rasanya sakit sekali.

\section{PENUTUP}

\section{Simpulan}

Berdasarkan penelitian yang telah dilakukan berkaitan dengan kesantunan teori Leech dalam dialog komunikasi terapeutik antara bidan dan ibu hamil pada Klinik Bidan Emmy, yang terletak di Jalan Kemakmuran, Mekarjaya, Kecamatan Sukmajaya, Depok dan dianalisis menggunakan prinsip kesantunan Geoffrey Leech dapat ditarik simpulan sebagai berikut.

Dari 21 dialog, terdapat 17 dialog yang menaati prinsip kesantunan dan 4 yang melanggar. Dialog yang menaati prinsip kesantunan yaitu dialog (1) dan dialog (2) yang menaati maksim kebijaksanaan (Tact Maxim), dialog $(4,5,6,7)$ yang menaati maksim kedermawanan (Generosity Maxim), dialog $(8,9,10,11)$ yang menaati maksim penghargaan (Approbation Maxim), dialog (12, 13,14) yang menaati maxim keserderhanaa (Modesty Maxim), dialog (15) yang menaati maksim permufakatan (Agreement Maxim), serta dialog $(19,20,21)$ yang menaati maksim simpati (Sympathy Maxim). Sedangkan dialog yang melanggar prinsip kesantunan adalah dialog (3) melanggar maksim kebijaksanaan (Tact Maxim), dan dialog $(16,17,18)$ melanggar maksim permufakatan (Agreement Maxim).

Dialog komunikasi terapeutik antara bidan dan ibu hamil pada Klinik Bidan Emmy, yang terletak di Jalan Kemakmuran, Mekarjaya, Kecamatan Sukmajaya, Depok, juga telah menunjukkan tercapainya tujuan komunikasi terapeutik yakni komunikasi yang bertujuan agar pasien merasa senang dan dihargai serta merasa tenang dengan kondisi yang dialami. 


\section{DAFTAR PUSTAKA}

Agus M, Hardjana. 2003. Komunikasi Intrapersonal \& Komunikasi Interpersonal. Yogyakarta: Kanisius.

Dardjowidjojo, Soenjono. 2005. Psikolinguistik: Pemahaman Bahasa Manusia. Jakarta: Yayasan obor Indonesia.

Gunarwan, Asim. 2007. Pragmatik: Teori dan Kajian Nusantara. Jakarta : Universitas Atma Jaya.

Markhamah dan Atiqa Sabardila. 2020. "Kesantunan Berbahasa: Perspektif Terjemahan Al Quran Dan Hadis" Makalah disampaikan dalam Seminar Nasional "Kesantunan Berbahasa dalam Berbagai Perspektif" di Pascasarjana Universitas Muhamamdiyah Surakarta. 27 Desember 2012. Web. 3 Pebruari.

Mulyana, Deddy. 2008. Ilmu Komunikasi Suatu Pengantar. Bandung : Rosda. 2005. Metodologi Penelitian Komunikasi. Bandung: Remaja Rosdakarya.

Nadar, F. X. 2013. Pragmatik dan penelitian Pragmatik. Yogyakarta: Graha Ilmu.

Nursalam, Pariani. 2001. Pendekatan Praktis Metodologi Riset Keperawatan. Jakarta: Sagung Seto.

Patty, Marlen Febiyana, Dewi Kartika Sari, dan Yafet Pradikatama. 2015. "Hubungan Komunikasi Terapeutik Perawat Terhadap Tingkat Stres Pasien di Ruang Neurologi Rumah Sakit Umum Daerah dr M.Haulussy Ambon". Jurnal Komunikasi, Vol 9, No 2, April 2015.

Potter dan Perry. 2015. Buku Ajar Fundamental Keperawatan: Konsep, Proses Praktek. Edisi 4 Vol.1. Jakarta. EGC.

Rahardi, R. Kunjana. 2015. Pragmatik: Kesantunan Imperatif Bahasa Indonesia. Jakarta: Erlangga.

Rusmini. 2006. Hubungan komunikasi terapeutik dengan stres pasien di RSU Doris Sylvanus Palangkaraya.

Suryani. 2013. Komunikasi Terapeutik Teori dan Praktik ED.2. Jakarta: Kedokteran EGC.

Taufik, M dan Juliane. 2010. Komunikasi Terapeutik dan Konseling dalam Praktik Kebidanan. Jakarta: Salemba Medika. 